\section{Commentary: Diastolic (dys) function after Fontan completion: Where is the dysfunction?}

\author{
Reena M. Ghosh, MD, ${ }^{\mathrm{a}}$ and \\ Katsuhide Maeda, MD, $\mathrm{PhD}^{\mathrm{b}}$
}

Characterizing ventricular mechanics in patients with Fontan physiology has been and remains a rich area for research. Previously published studies conducted using echocardiography-based techniques such as Doppler tissue imaging and speckle tracking ${ }^{1-3}$ have demonstrated impaired diastolic function in patients with single ventricles as compared with healthy controls. Recent data also suggest that the diastolic impairment is worse in patients with a single right ventricle versus a single left ventricle. ${ }^{4}$

In the last decade, advances in 4-dimensional (4D) flow cardiac magnetic resonance (CMR) techniques have enabled imagers to analyze specific components of ventricular flow patterns, bringing us one step closer to understanding what "impaired diastolic function" really means. Work by Eriksson and colleagues ${ }^{5}$ and Stoll and colleagues ${ }^{6}$ has validated CMR-based methods for separating left ventricular end-diastolic volume (EDV) into functional flow components. When analyzing these components in patients with asymptomatic dilated cardiomyopathy (DCM) and in healthy controls, the patients with DCM had multiple indices of impaired diastolic flow patterns, including increased residual volume percentage and decreased direct flow (blood that enters and leaves the left ventricular in the same cardiac cycle). ${ }^{7}$ In a 2019 study $^{8}$ of adults with DCM or ischemic cardiomyopathy compared with healthy adults, ventricular flow components were used to calculate average kinetic energy throughout the cardiac cycle. Data analysis

\footnotetext{
From the ${ }^{\mathrm{a}}$ Division of Cardiology, Department of Pediatrics, and ${ }^{\mathrm{b}}$ Division of Cardiothoracic Surgery, Department of Surgery, Children's Hospital of Philadelphia, Philadelphia, $\mathrm{Pa}$.

Disclosures: The authors reported no conflicts of interest.

The Journal policy requires editors and reviewers to disclose conflicts of interest and to decline handling or reviewing manuscripts for which they may have a conflict of interest. The editors and reviewers of this article have no conflicts of interest.

Received for publication July 9, 2021; revisions received July 9, 2021; accepted for publication July 9, 2021; available ahead of print July 15, 2021.

Address for reprints: Katsuhide Maeda, MD, PhD, Division of Cardiothoracic Surgery, Department of Surgery, Children's Hospital of Philadelphia, Philadelphia, PA 19104 (E-mail: maedak@chop.edu).

J Thorac Cardiovasc Surg 2022;163:1208-9

$0022-5223 / \$ 36.00$

Copyright (C) 2021 by The American Association for Thoracic Surgery

https://doi.org/10.1016/j.jtcvs.2021.07.016
}

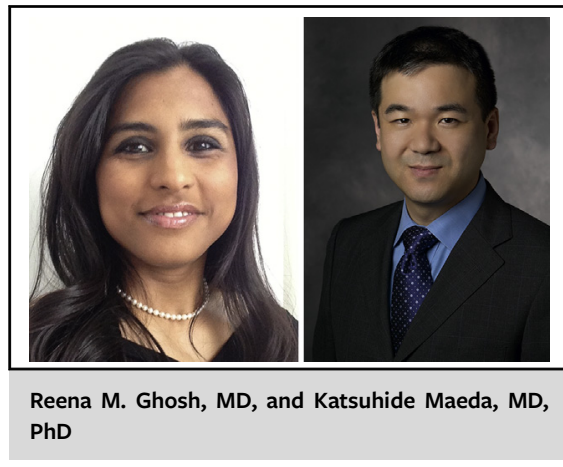

CENTRAL MESSAGE

4D flow CMR analysis of ventricular flow components may reveal insights into impairment of diastolic function after Fontan

operation.

demonstrated not only the impairments in diastolic flow patterns as seen in earlier work by Eriksson and colleagues but also an independent predictive relationship between average kinetic energy and performance on 6-minute walk test.

In this issue of the Journal, Stone and colleagues ${ }^{9}$ have applied these previously validated 4D flow CMR techniques to assess functional flow components within the systemic ventricle of patients after Fontan completion. Their findings demonstrated that EDV was significantly greater in patients with hypoplastic left heart syndrome compared with those with hypoplastic right heart syndrome and controls. Despite the difference in EDV based on ventricular morphology, results using the particle tracking 4D flow techniques revealed that single-ventricle patients as a whole had impaired indices of diastolic function, including increased residual volume percentage and decreased direct flow, when compared with healthy volunteers. Furthermore, both indices were shown to correlate independently with ejection fraction.

These findings provide insight into the mechanisms involved diastolic dysfunction. One could surmise that increasing direct flow by optimizing atrial contraction or atrioventricular synchrony may improve diastolic function. Yet, we must read the results with caution-while there are significant differences in ventricular flow patterns between the groups, the etiology of those differences and their relationship to clinical status remains unknown. 
Overall, this study is an excellent example of how 4D flow CMR can be used to gain quantitative insights into the pathophysiology of single-ventricle circulation. As 4D flow techniques become incorporated into clinical CMR studies, serial assessment of ventricular flow patterns may provide a noninvasive method of detecting subclinical disease.

\section{References}

1. Sato T, Calderon RJ, Klas B, Pedrizzetti G, Banerjee A. Simultaneous volumetric and functional assessment of the right ventricle in hypoplastic left heart syndrome after Fontan palliation, utilizing 3-dimensional speckle-tracking echocardiography. Circ J. 2020;84:235-44.

2. Michel M, Logoteta J, Entenmann A, Hansen JH, Voges I, Kramer HH, et al. Decline of systolic and diastolic 2D strain rate during follow-up of HLHS patients after Fontan palliation. Pediatr Cardiol. 2016;37:1250-7.
3. Campbell MJ, Quartermain MD, Cohen MS, Faerber J, Okunowo O, Wang Y, et al Longitudinal changes in echocardiographic measures of ventricular function after Fontan operation. Echocardiography. 2020;37:1443-8.

4. Kaneko S, Khoo NS, Smallhorn JF, Tham EB. Single right ventricles have impaired systolic and diastolic function compared to those of left ventricular morphology. J Am Soc Echocardiogr. 2012;25:1222-30.

5. Eriksson J, Dyverfeldt P, Engvall J, Bolger AF, Ebbers T, Carlhäll CJ. Quantification of presystolic blood flow organization and energetics in the human left ventricle. Am J Physiol Heart Circ Physiol. 2011;300:H2135-41.

6. Stoll VM, Loudon M, Eriksson J, Bissell MM, Dyverfeldt P, Ebbers T, et al. Testretest variability of left ventricular 4D flow cardiovascular magnetic resonance measurements in healthy subjects. J Cardiovasc Magn Reson. 2018;20:15.

7. Eriksson J, Bolger AF, Ebbers T, Carlhäll CJ. Four-dimensional blood flowspecific markers of LV dysfunction in dilated cardiomyopathy. Eur Heart J Cardiovasc Imaging. 2013;14:417-24.

8. Stoll VM, Hess AT, Rodgers CT, Bissell MM, Dyverfeldt P, Ebbers T, et al. Left ventricular flow analysis. Circ Cardiovasc Imaging. 2019;12:e008130.

9. Stone ML, Schafer M, Dimaria MV, von Alvensleben JC, Campbell DN, Jaggers $\mathrm{J}$, et al. Diastolic inflow is associated with inefficient ventricular flow dynamics in Fontan patients. J Thorac Cardiovasc Surg. 2022;163:1195-207.

\section{Commentary: Time to climb the ladder of causation}

\section{William M. DeCampli, MD, PhD}

In a book published in 2018, Turing Awardee Judea Pearl and Dana MacKenzie wrote of the need for science to climb the "ladder of causation," moving above association, passing through intervention, and finally arriving at counterfactuals, where one can finally address causation. ${ }^{1}$ Stone and colleagues $^{2}$ used cardiac magnetic resonance imaging to calculate previously described 4 components of end diastolic blood volume in 10 patients with hypoplastic left heart syndrome, hypoplastic right heart syndrome, and controls. ${ }^{2}$ Compared with controls, patients with hypoplastic left heart syndrome and hypoplastic right heart syndrome had less direct flow volume (DF) and more residual volume (as a percentage of end diastolic volume [EDV]). Based on

\footnotetext{
From the College of Medicine, University of Central Florida, and The Heart Center, Arnold Palmer Hospital for Children, Orlando, Fla.

Disclosures: The author reported no conflicts of interest.

The Journal policy requires editors and reviewers to disclose conflicts of interest and to decline handling or reviewing manuscripts for which they may have a conflict of interest. The editors and reviewers of this article have no conflicts of interest.

Received for publication July 28, 2021; revisions received July 28, 2021; accepted for publication July 28, 2021; available ahead of print Aug 3, 2021.

Address for reprints: William M. DeCampli, MD, PhD, The Heart Center, Arnold Palmer Hospital for Children, 83 W Miller St, Orlando, FL 32813 (E-mail: William.decampli@orlandohealth.com).

J Thorac Cardiovasc Surg 2022;163:1209-10

0022-5223/\$36.00

Copyright (C) 2021 by The American Association for Thoracic Surgery

https://doi.org/10.1016/j.jtcvs.2021.07.046
}

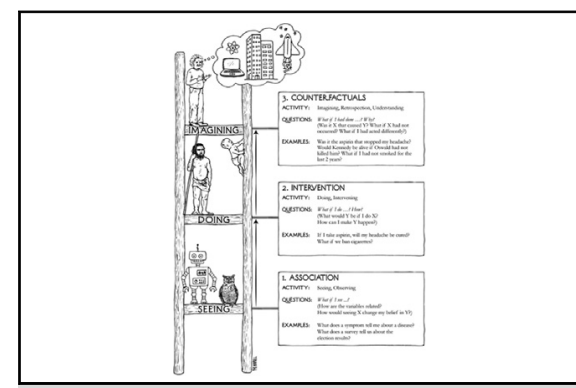

Associations lie at the bottom of the Ladder of Causation. Let's climb the ladder!' (C) 2018. Reprinted by permission of Basic Books, an imprint of Hachette Book Group, Inc.

CENTRAL MESSAGE

The association of CMR-derived components of diastolic volume with conventional measures of ventricular function is intriguing, if not mysterious. Science must determine the causal relationships.

these measurements, the authors concluded that these patients have "inefficient flow patterns" and diastolic dysfunction.

The use of these diastolic component volumes as indicators of diastolic function and originated in a 2011 article that hypothesized that diastolic flow patterns could 